\title{
You are Cancelled: Virtual Collective Consciousness and the Emergence of Cancel Culture as Ideological Purging
}

\author{
Joseph Ching Velasco \\ De La Salle University. ORCID ID: oooo-0oo2-7098-8216. \\ Email: josephchingvelasco@gmail.com
}

\begin{abstract}
Social networking platforms were originally conceived to enable individuals to engage in various forms of online interactions. As social networking sites robustly permeated different facets of society, they have been commonly grouped under the more generic term "social media." Social media has become a powerful force in contemporary life, paving the way for the rise of digital participatory cultures and social movements. More recently, the culture of cancellation has entered the vernacular of digital culture, primarily targeted at public figures who break the loose norms of social acceptability. Specifically, cancel culture is a form of public shaming initiated on social media to deprive someone of their usual clout or attention with the aim of making public discourse more diffused and less monopolized by those in positions of privilege. Conversely, cancel culture has also been framed as a form of intolerance against opposing views. In this essay, I unpack the nuances and implications of cancel culture through Neil Alperstein's concept of "virtual collective consciousness." In Southeast Asia, particularly the Philippines, cancel culture has become more demonstrable on social media. I will use a case study of a public figure from the Philippines who has been subjected to cancel culture in order to examine the complexity of this social phenomenon.
\end{abstract}

Keywords: Cancel Culture, Social Media, Public Shaming, Cancelledt, Celebrity, woke, wokeism, influencer

\section{Introduction}

Social networking platforms were originally conceived to allow individuals to engage in different forms of online interactions. This technology robustly permeated different facets of society, it has morphed into a generic term called social media. Such has become a powerful force in contemporary life, paving the way for the rise of digital participatory cultures and social movements. Social media has certainly brought forth boons and banes in modern life, from the convenience of shopping online to the pervasiveness of deliberate networked disinformation. Social media has allowed individuals to be constantly connected despite distance and other physical limitations. However, it also ushered in an always-on digital persona and continuous communication (Velasco, 2020). Everyone is glued to their devices and the online and real-life divide has been blurred. Sociologist Manuel Castells posits important terminologies to critically describe the way interaction has been shaped in the digital age. More specifically, he coined the term hypersociality, which is a transformation of sociability. He argues:

The network society is a hypersocial society, not a society of isolation. People, by and large, do not fake their identity in the Internet, except for some teenagers experimenting with their lives. People fold the technology into their lives, link up virtual reality and real

(C) AesthetixMS 2020. This Open Access article is published under a Creative Commons Attribution Non-Commercial 4.o International License (http://creativecommons.org/licenses/by-nc/4.o/), which permits non-commercial re-use, distribution, and reproduction in any medium, provided the original work is properly cited. For citation use the DOI. For commercial re-use, please contact editor@rupkatha.com. 
virtuality, they live in various technological forms of communication, articulating them as they need it. (Castells, 2005, p. 11)

With the existence of hypersociality, the emergence of networked individualism has become more palpable. Castells (2005) argue that "the emergence of networked individualism, as social structure and historical evolution induce the emergence of individualism as the dominant culture of our societies, and the new communication technologies perfectly fit into the mode of building sociability along self-selected communication networks" (p. 12).

With this development in the intersection of society and technology, new forms of collectivities have been formed. Social media has not only become a prism for information exchange, it also paved the way for the rise of digital participatory cultures and social movements. It has become a contested site for competing forms of knowledge, culture, and ideology. The act of cancelling someone, thus, is one of those spontaneous collective practices initiated by social media users, without consideration for its possible ramifications. Undeniably, the culture of cancellation has become part and parcel of the vernacular of digital culture, primarily targeted against public figures who break the loose norms of social acceptability.

Scholarly discussions on cancel culture have been limited, which can possibly be attributed to the fear of being cancelled should arguments go against the dominant currents of certain social movements. Cancel culture is a manifestation of "wokeism" which is "an ideology that views reality as socially constructed and defined by power, oppression and group identity" (Beiner, 2020). Anyone can be cancelled, no one is spared, even myself.

In this essay, I will unpack the nuances and implications of cancel culture through Neil Alperstein's concept of "virtual collective consciousness." Particularly, I will delineate cancel culture as a sporadic collective social movement leveled against individuals who infringe on the loose norms of social acceptability. Celebrity culture has evolved along with the new developments in social technologies. Consequently, the public has deployed new ways of policing misbehavior through social media. Who, then, is the yardstick for acceptable behavior in today's hypersocial reality? Simply put, on social media, any user can be the judge, jury, and executioner of any individual. Cancellation spreads like wildfire on social media and it is "virulently uncontrollable" (Lu, 2019).

\section{Virtual Collective Consciousness and the Transformation of Celebrity Culture}

Alperstein (2019) traced the cultural shifts that occurred as social media became more pervasive. He also posits the concept of virtual collective consciousness, where thoughts and beliefs are merged on social media. When thoughts and beliefs coalesce, it becomes the collective consciousness of similarly minded individuals. He further explains:

One's inner world is turned outward to become part of a network, including membership in a cluster or crowd. To a degree the virtual collective consciousness represents the expression of our inner mind wandering, stream of consciousness, daydreams and nocturnal dreams, turned outward in a spontaneous, synchronous manner with in a social network, based partially on mediated social connections with celebrities and other people who are present and active on the social network. (Alperstein, 2019, p. 204)

As elegant as it may sound, it bears similarity to an echo chamber, where similarly minded individuals only hear what they wish to hear. Anything that might be contrary to their line of thinking and preferences is deemed undesirable. Social media users follow pages that are aligned 
with their views and unfollow those which seem to be inconsistent with their inclinations. As one's thoughts and ideas become in sync with other mediated connections on social media, it becomes more challenging to accommodate ideas contrary to the dominant ideological climate.

This is the current digital social environment where everyone is subjected to. Celebrities, influencers, public figures, as individuals who wield influence on their respective networks, are strictly held against the loose standard of current social acceptability. Celebrities, before, are a production of media institutions. Hearn and Schoenhoff (2015) argue that the concept of celebrity is a highly complex entity; they are a form of "constructed subjectivity consisting of distinct sets of self-referential, attention-seeking, market-aware practices." (p. 196) Celebrities are spectacles that are constantly blasted on different media that allows for sustained interest by the public. However, that has all changed when social media became a platform for self-publishing. Traditional media institutions as gatekeepers have been cut off from the process and celebrities can now directly access the public through the digital networks that they have cultivated. Equally, the public can directly reach out to these individuals mediated through technology. Celebrities who use social media can now be considered influencers. In a similar vein, social media influencers have also become a form of celebrity.

As mentioned earlier, there seems to be a vague yardstick of social acceptability which public figures are held against. When public figures such as celebrities and influencers are subject of scandals, there are usually four possible public reactions: condemnation, indifference, resentment, and approval (Cashmore, 2006). However, events or behaviors that are deemed scandalous are also constantly evolving. It is, therefore, difficult to assess which types of transgression will result in approval or condemnation. As consumers of media, scandals do appeal to the public. Nayar (2006) argues celebrities appeal to us because they make two contradictory moves, that is, humanize larger than life figures and "enhance the envied celebrity's larger-thanlife stature as one who can indulge in behavior, situations and acts that we ordinary people cannot" (p. 113).

A few decades ago, public figures can weather scandals gracefully and come out unscathed. But with the direct link of these figures to the public through technology, escaping the scrutinizing public gaze is impossible. One wrong word in a post, a statement contrary to the dominant narrative, an "insensitive" joke, or even a "problematic" essay will open the floodgates of vitriol from social media users. A public shaming ensues, and you become cancelledt.

\section{What it Means to Be Cancelled: The Expurgation from Public Discourse}

At this point, "almost everyone worth knowing has been cancelled by someone" (Bromwich, 2018). Those who were cancelled have breached the line of social acceptability, according to unmarked and entirely ambiguous norm of today's social media climate. "It is an act of withdrawing from someone whose expression - whether political, artistic, or otherwise - was once welcome or at least tolerated, but no longer is" (Bromwich, 2018). In addition, it is a tactic of "trying to erase someone from public discourse - either through publicly shaming, deplatforming, or demanding that they be fired" (Beiner, 2020). There is no clear-cut parameter that someone merits cancellation. With the ambiguous nature cancel culture, a person who undergoes this form of public shaming likewise has an extremely vague and unclear path to redemption. Some individuals tout cancel culture as a manifestation of agency. Professor Lisa Nakamura from the University of Virginia claims that cancel culture is the "ultimate expression of agency" (Bromwich, 2018). In a similar vein, Professor Lisa Nakamura from the University of Michigan notes that 
cancelling someone is a form of "cultural boycott" (Bromwich, 2018). This phenomenon is probably one of the greatest displays of the democratization of discourse. Natalie Pang from the National University of Singapore argues that marginalized voices are now heard, and discourse is less dominated by individuals who are in positions power and privilege (Lim, 2020).

Despite the provocative notions that cancel culture brings forth, it is also simultaneously a complicated social movement. Not everyone is in agreement of the greater purpose of cancel culture. Walid Jumblatt Abdullah from Nanyang Technological University opines that "cancelling someone is ultimately a power play: that power can be deprived from institutions and formal authority, or just popular opinion" (Lim, 2020). The problem lies with the "lack of understanding on how to engage with it on its own terms" (Beiner, 2020).

One of the most recent figures who got cancelled is J.K. Rowling. On June 6, 2020, J.K. Rowling tweeted, "If sex isn't real, there's no same-sex attraction. If sex isn't real, the lived reality of women globally is erased. I know and love trans people, but erasing the concept of sex removes the ability of many to meaningfully discuss their lives. It isn't hate to speak the truth." This seems to have offended the transgender community, which led to her cancellation. Consequently, fan sites dedicated to Harry Potter such as Mugglenet and The Leaky Cauldron have cut ties with J.K Rowling because of her trans-offensive tweet (Luu, 2020).

Her case is not unique as other renowned public figures have been subjected to cancel culture. There is now a push back against the powerful force emanating from the culture of cancellation. In a collective response, 150 writers and academics, including J.K. Rowling, Noam Chomsky, and Salman Rushdie, wrote an open letter to Harper's Magazine (2020) calling attention to the rising intolerant climate emanating from the political left. An excerpt from the letter reads:

While we have come to expect this on the radical right, censoriousness is also spreading more widely in our culture: an intolerance of opposing views, a vogue for public shaming and ostracism, and the tendency to dissolve complex policy issues in a blinding moral certainty. We uphold the value of robust and even caustic counter-speech from all quarters. But it is now all too common to hear calls for swift and severe retribution in response to perceived transgressions of speech and thought.

An invitation to open discussion seems to be the way forward in this extremely complicated cultural movement. Walid Jumblatt Abdullah cautions that the growing trend of cancellation is stifling open debate and intensifies self-censorship among public figures (Lim, 2020). Essentially, the culture of cancellation has become an apparatus to enact an ideological purge.

\section{The Emergence of Cancel Culture in Southeast Asia: A Case from the Philippines}

Cancel culture has also reached the shores of Southeast Asia. Lim (2020) reveals that this social movement may have originated from the West but it has become a force for social change among the youth of Asia. In the section, I will use a case study of a celebrity from the Philippines who was cancelled because of a social media infraction. Cat Arambulo-Antonio is an "outspoken blogger, social media personality, and entrepreneur" (Williams, 2019). She also has been a judge in the reality TV show The Apartment. At the height of the Covid-19 pandemic in the Philippines, she posted an Instagram story disparaging individuals who were stuck at security checkpoints. In the Instagram story that she posted on March 16, 2020, it shows a news report of CNN showing a man who was handcuffed and being led to a police vehicle. She then unleashed a profanity-laden 
commentary on why people should stay at home. Specifically, she said, "my god, why don't you mother ${ }^{* * * * *}$ s just stay at home? Stay at home! Don't you guys get it? Tigas ng ulo [Hard headed], this is exactly why they need the military because you $\mathrm{f}^{* * * * *}$ s won't stay at home. Guy's come on." The following day, she became one of the Twitter trending topics in the Philippines. It should be noted that the deficiency of government response to the pandemic has forced workers to go out and continue their livelihoods despite the risks.

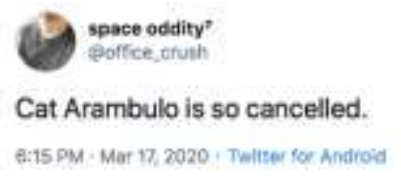

Figure 1: A tweet calling for Cat ArambuloAntonio's cancellation

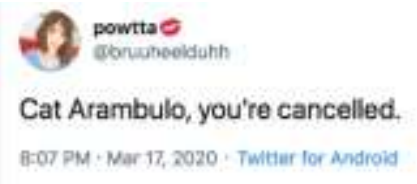

Figure 2: A tweet declaring Cat ArambuloAntonio is cancelled

Due to the immense backlash that her Instagram story has garnered, calls for her cancellation have become evident on Twitter. As an example, Figure 1 shows a Twitter user seeking to cancel her, which reads, "Cat Arambulo is so cancelled." Another tweet on Figure 2 reads, "Cat Arambulo, you're cancelled." Subsequently, other users have started to tag brands affiliated with Cat Arambulo-Antonio to call attention toward her remarks.

\section{nico quejano}

Oh apparently here are the brands Cat Arambulo worked with.

Hello@Huawei@nbsalert @uratex @SariwonPH $@$ @rganiqueAcai @ArielDetergente just so you have an idea how insensitive Cat Arambulo is.

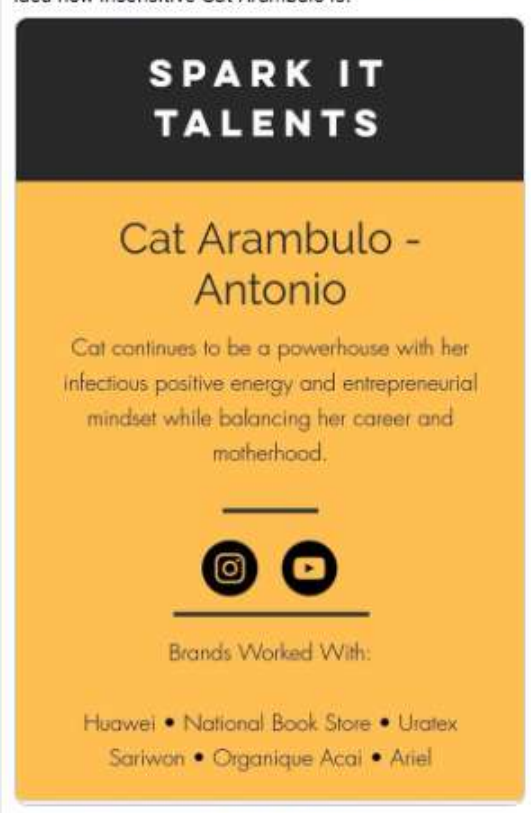

7:15 PM - Mar 17, 2020 - Twitter for Android

Figure 3: A tweet calling attention to the brands that Cat Arambulo-Antonio is associated with

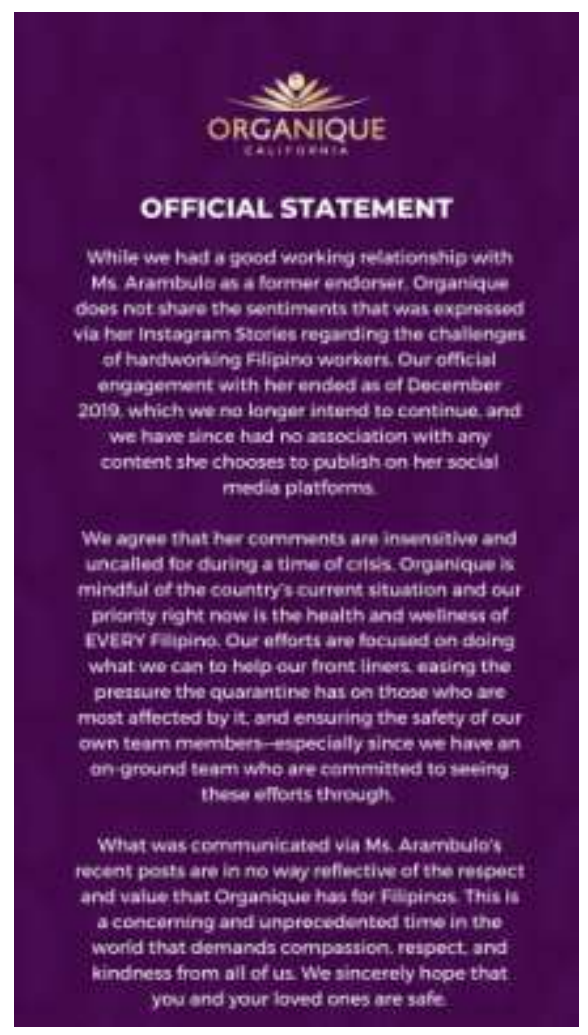

Figure 2: The brand Organique distancing itself from Cat-Arambulo Antonio 
Figure 3 depicts a twitter user tagging the different brands that Cat Arambulo-Antonio have work with. In addition, Figure 4 is an official statement from Organique distancing itself from Cat Arambulo-Antonio. She was taken to the court of public opinion, which is Twitter, and was deemed cancelledt. Should anyone defend or attempt to give her a path to redemption, they might suffer a comparable consequence. She now serves as a vivid reminder for public figures, celebrities, influencers to consistently censor themselves, their content, and ensure that it complies with the dominant ideological climate.

\section{Conclusion and Future Directions}

This essay unpacked and examined the culture of cancellation in today's social media environment. The culture of cancellation is a highly complicated social movement. On one hand, it is one of the highest displays of the democratization of discourse. On the other hand, it is also a force for censoriousness and an intolerance for ideas that run contrary to the dominant acceptable social norms. Some contemplate that there is a better way to go about this form of calling attention to inappropriate behavior. In this essay, I used the case of Cat Arambulo-Antonio as a celebrity who was cancelled on social media because of inappropriate remarks directed to the public. In the Philippine context, there seems to be no push back against this form of public shaming. Additionally, it is gaining strength since it has become an apparatus for the modification of online behavior.

Public humiliation is not new and has existed for centuries. History has shown that humanity has devised a multitude of creative yet gruesome ways of shaming an individual for alleged social and legal infractions e.g. public flogging, wearing a dunce cap, forced public exposure, and public caning. The concept of cancelling someone is similar to those mentioned but is specifically designed for the digital age in the midst of hypersociality. As such, the pervasiveness of the culture of cancellation is disobliging of open debate; it is a form of critique that is destructive. Perhaps, it may further evolve toward a more constructive form of critique, focused on the action instead of the person. As they say, everyone has skeletons in their closets; anyone, therefore, can be subjected to the culture of cancellation.

\section{References}

Alperstein, N. M. (2019). Celebrity and Mediated Social Connections. Cham: Springer.

Beiner, A. (2020, July 17). Sleeping woke: Cancel culture and simulated religion. Medium. Retrieved from: https://medium.com/rebel-wisdom/sleeping-woke-cancel-culture-and-simulated-religion5 f96af2cc107

Bromwich, J. E. (2019, June 28). Everyone is cancelled. The New York Times. Retrieved from: https://www.nytimes.com/2018/o6/28/style/is-it-canceled.html

Cashmore, E. (2006). Celebrity/Culture. New York: Routledge.

Castells, M. (2005). The networked society: From knowledge to policy. In M. Castells \& G. Cardoso (Eds.), The Network Society: From Knowledge to Policy (pp. 3-22). Washington: Center for Transatlantic Relations.

Harper's Magazine. (2020, July 7). A letter and justice on open debate. Retrieved from: https://harpers.org/aletter-on-justice-and-open-debate/ 
Hearn, A., \& Schoenhoff, S. (2016). From celebrity to influencer: Tracing the diffusion of celebrity value across the data stream. In P. D. Marshall \& S. Redmond (Eds.), A Companion to Celebrity (pp. 194211). West Sussex: Wiley.

Lim, K. (2020, July 19). Cancel culture: How Asia's 'woke brigade' became a political force. South China Morning Post. Retrieved from: https://www.scmp.com/week-asia/lifestyleculture/article/3093736/cancel-culture-how-asias-woke-brigade-became-political

Lu, C. (2019, December 18). Cancel culture is chaotic good. Jstor Daily. Retrieved from: https://daily.jstor.org/cancel-culture-is-chaotic-good/

Luu, C. (2020, July 2). The Harry Potter fandom officially cancelled J.K. Rowling. In Style. https://www.instyle.com/celebrity/jk-rowling/harry-potter-fansites-no-longer-support-jk-rowling

Nayar, P. K. (2009). Seeing Stars: Spectacle, Society, and Celebrity Culture. New Delhi: Sage.

Velasco, J. C. (2020). Millennials as digital natives: Examining the social media activities of the Ygeneration. Pertanika Journal of Social Science and Humanities, 28(3).

Williams, S. J. P. (2019, July 12). Entrepreneur \& social media personality Cat Arambulo-Antonio reveals her life mantra: Strong mind, active body, happy heart. Tatler Philippines. Retrieved from https://ph.asiatatler.com/society/entrepreneur-social-media-personality-cat-arambulo-antonioreveals-her-life-mantra-strong-mind-activ

Joseph Ching Velasco is a PhD candidate in sociology at De La Salle University, Manila. He also attended short courses on global health at Hokkaido University under the Sakura Exchange Program in Science administered by Japan Science and Technology Agency. Currently, he is the Managing Editor of the Asia-Pacific Social Science Review. His works have appeared in journals such as Kritika Kultura, Pertanika Journal of Social Science and Humanities, and Mediterranean Journal of Social Sciences. He does research on the areas of generational sociology, digital cultures, work ethic, burnout, and Chinese-Filipino culture. 